\title{
PAPERS
}

\section{5 \\ Interactions between people's diet and their smoking habits: the dietary and nutritional survey of British adults //}

Barrie MLMargetts, Alan A/Jackson

\begin{abstract}
Objective-To compare diet, nutrient intakes, and biochemical measures between smokers and non-smokers.

Design-Analysis of data collected in cross sectional survey conducted in 1986 and 1987. Subjects were recruited from electoral wards in England, Wales, and Scotland to reflect the regional distribution of the population.

Subjects-2197 subjects ( $70 \%$ of those asked) aged between 16 and 64 undertook dietary assessment. Of these, 1842 subjects were considered to have kept a record typical of their usual dietary intake and had given data on smoking, and their results were analysed: 1224 non-smokers (631 men), 359 light smokers (166 men), and 259 heavy smokers (153 men).
\end{abstract}

Main outcome measures-Differences in dietary, nutrient, and biochemical mẹasures between nonsmokers and smokers.

Results-Smokers ate more white bread, sugar, cooked meat dishes, butter, and whole milk and less wholemeal bread, high fibre breakfast cereals, fruit, and carrots. Smokers had lower intakes of polyunsaturated fat, protein, carbohydrate, fibre, iron, carotene, and ascorbic acid. Adjusting for other covariates did not substantially alter the pattern of intakes. At the same dietary intake of carotenoids smokers were more likely to have lower circulating serum $\beta$ carotene concentrations than non-smokers.

Conclusions-The diet and nutrient intakes and circulating levels of nutrients of smokers were different from those of non-smokers. Smokers were more likely to have an imbalance between the dietary intake of antioxidant nutrients and the metabolic demand for antioxidant protection. This imbalance is likely to make smokers more susceptible to oxidative damage. Smokers are at increased risk of chronic disease because their diets are different and because smoking creates an altered pattern of demand for specific nutrients. The diets of smokers not only fail to meet the unusual requirements for specific nutrients to satisfy the altered pattern of demand but are likely to exacerbate the damage caused by smoking.

\section{Introduction}

Smoking accounts for more than one third of all deaths in middle age, and although rates of smoking are declining among adults they are increasing in adolescents. ${ }^{1}$ Smoking cigarettes may be associated with a change in dietary habits which may contribute to the increased risk of coronary vascular disease and other disorders in smokers compared with nonsmokers. There have been several studies of the dietary habits of smokers in the United Kingdom²: smokers tend to have lower dietary intakes of fibre, carotene, thiamin, vitamin $\mathrm{E}$, and iron. Although the total fat intake of smokers and non-smokers is generally similar, smokers tend to have a lower ratio of polyunsaturated to saturated fat. Smokers have lower dietary intakes of a number of antioxidants, and, given the high free radical load associated with smoking, it has been suggested that the imbalance between antioxidant intakes and free radical load results in greater potential for oxidative damage to tissues. ${ }^{3}$ For example, recent studies have indicated that the oxidised form of low density lipoprotein is more likely to lead to the formation of foam cells in the endothelium and subsequently lead to atheroma. ${ }^{4}$ Smokers with higher circulating levels of low density lipoprotein and increased oxidative stress may therefore be more likely to have higher levels of oxidised low density lipoprotein and so be at increased risk of atherosclerosis. It has also been suggested that imbalances between antioxidants and free radicals may be important in the aetiology of cancer. ${ }^{5}$

There have been studies of selected groups to look at aspects of diet and disease and at biochemical changes and disease, but no studies have looked at the interaction of dietary factors with intermediate markers for disease risk in a sample of smokers and non-smokers representative of the population of Britain. From 1986 to 1987 a national survey of adults in Britain was conducted by the Ministry of Agriculture, Fisheries and Food, the Department of Health, and the Office of Population Censuses and Surveys. ${ }^{6}$ This survey provided a unique opportunity to explore the relation between diet, smoking, and other risk factors for major chronic disease.

\section{Subjects and methods}

The data used in the present analysis were taken from those collected in the dietary and nutritional survey of British adults. ${ }^{6}$ Subjects aged 16-64 who were living in private households in Britain were recruited into the study by means of a multistage random probability design. The electoral roll was used as the sampling frame. The frame was stratified by region, and in each major stratum wards were ranked according to the proportion of heads of households in various economic groups. A total of 120 wards were selected as first stage units to reflect the sociodemographic profile of Britain. From each ward 32 addresses were selected and one individual from each household was selected from each address for inclusion using the technique developed by Kish. ${ }^{7}$ The subjects were asked to complete a short questionnaire covering personal details and general household information as well as general information on dietary habits, including the use of supplements. Each subject was also asked to weigh and record all food and drink consumed both in and outside the home for seven days: the subjects were given a set of food scales and booklets in which to 
record the information. The methods are described in greater detail elsewhere. ${ }^{\circ}$

The subjects' heights (to the nearest $\mathrm{mm}$ ) and weights were measured with a portable stadiometer and a digital personal weighing scale (calibrated to $200 \mathrm{~g}$ ) respectively and were used to calculate body mass index (weight $\left.(\mathrm{g}) /(\text { height }(\mathrm{m}))^{2}\right)$. Systolic and diastolic blood pressures were measured three times with the subjects sitting by means of an automatic sphygmomanometer, which the interviewers had been trained to use. The subjects were asked to collect all urine passed during 24 hours. A $20 \mathrm{ml}$ sample of venous blood was taken and kept cool and out of direct sunlight until it could be analysed: haematological profile; serum concentrations of albumin, total cholesterol, and high density lipoprotein; and plasma concentrations of retinol, $\alpha$ and $\beta$ carotene, and tocopherol were measured.

Data were analysed with sPSs, and differences between groups were assessed with analysis of variance and analysis of covariance when the effects of other covariates were considered. To determine which group means were significantly different the least significance difference ranges test was used.

\section{Results}

A total of 2197 subjects ( $70 \%$ of those asked) completed the dietary record. During the interviews

TABLE I-Characteristics of 1842 subjects by smoking status. Values are means (95\% confidence intervals) unless stated otherwise

\begin{tabular}{|c|c|c|c|c|}
\hline & \multicolumn{3}{|c|}{ Smoking status } & \multirow[b]{2}{*}{$\begin{array}{c}\mathrm{p} \\
\text { Value }^{\star}\end{array}$} \\
\hline & None & $\underset{(<20 \text { cigarettes/day })}{\text { Light }}$ & $\begin{array}{c}\text { Heavy } \\
(\geqslant 20 \text { cigarettes/day })\end{array}$ & \\
\hline \multicolumn{5}{|c|}{ Men } \\
\hline $\begin{array}{l}\text { No of subjects } \\
\text { Age (years) } \\
\% \text { Of subjects in non-manual } \\
\text { occupations } \\
\text { Alcohol consumption }(\mathrm{g} / \text { day) } \\
\text { Body mass index }\left(\mathrm{kg} / \mathrm{m}^{2}\right) \\
\text { Systolic blood pressure }(\mathrm{mm} \mathrm{Hg})\end{array}$ & $\begin{array}{l}631 \\
38 \cdot 5(37 \cdot 4 \text { to } 39 \cdot 6) \dagger \\
52 \\
22 \cdot 5(20 \cdot 3 \text { to } 24 \cdot 6) \dagger \ddagger \\
25 \cdot 0(24 \cdot 8 \text { to } 25 \cdot 3) \\
125 \cdot 8(124 \cdot 6 \text { to } 126 \cdot 9)\end{array}$ & $\begin{array}{l}166 \\
36 \cdot 2(34 \cdot 0 \text { to } 38 \cdot 5) \dagger \\
34 \\
31 \cdot 4(25 \cdot 1 \text { to } 37 \cdot 7) \\
24 \cdot 5(23 \cdot 9 \text { to } 25 \cdot 1) \\
127 \cdot 3(124 \cdot 9 \text { to } 129 \cdot 6)\end{array}$ & $\begin{array}{l}153 \\
41 \cdot 3(39 \cdot 3 \text { to } 43 \cdot 3)^{\star} \\
34 \\
31 \cdot 7(25 \cdot 6 \text { to } 37 \cdot 1) \\
24 \cdot 7(24 \cdot 1 \text { to } 25 \cdot 2) \\
128 \cdot 4(126 \cdot 0 \text { to } 130 \cdot 7)\end{array}$ & $\begin{array}{l}0.005 \\
0.001 \\
0.001 \\
0.138 \\
0.114\end{array}$ \\
\hline \multicolumn{5}{|c|}{ Women } \\
\hline $\begin{array}{l}\text { No of subjects } \\
\text { Age (years) } \\
\% \text { Of subjects in non-manual } \\
\text { occupation } \\
\text { Alcohol consumption }(\mathrm{g} / \text { day) } \\
\text { Body mass index }\left(\mathrm{kg} / \mathrm{m}^{2}\right) \\
\text { Systolic blood pressure }(\mathrm{mm} \mathrm{Hg})\end{array}$ & $\begin{array}{l}593 \\
39 \cdot 7(38 \cdot 5 \text { to } 40 \cdot 8) \\
70 \\
6 \cdot 1(5 \cdot 4 \text { to } 6 \cdot 8) \ddagger \\
24 \cdot 6(24 \cdot 2 \text { to } 25 \cdot 0) \\
119 \cdot 3(118 \cdot 1 \text { to } 120 \cdot 6)\end{array}$ & $\begin{array}{l}193 \\
38 \cdot 6(36 \cdot 7 \text { to } 40 \cdot 6) \\
54 \\
8 \cdot 8(7 \cdot 2 \text { to } 10 \cdot 5) \\
24 \cdot 6(23 \cdot 7 \text { to } 25 \cdot 4) \\
116 \cdot 7(114 \cdot 6 \text { to } 118 \cdot 9)\end{array}$ & $\begin{array}{l}106 \\
40 \cdot 1(37 \cdot 8 \text { to } 42 \cdot 3) \\
46 \\
8 \cdot 2(5 \cdot 8 \text { to } 10 \cdot 6) \\
24 \cdot 4(23 \cdot 5 \text { to } 25 \cdot 3) \\
120 \cdot 1(117 \cdot 0 \text { to } 123 \cdot 2)\end{array}$ & $\begin{array}{c}0.599 \\
<0.001 \\
0.002 \\
0.931 \\
0.094\end{array}$ \\
\hline
\end{tabular}

the subjects were asked whether they were unwell and whether their diet during their recording of food intake was representative of their usual diet. Those who indicated that their diet was not representative were excluded from the present analysis, reducing the number of subjects to 1844 , of whom two gave no information on smoking. Of these subjects, 1483 had provided a blood sample. Basic descriptive data were published in the original report. ${ }^{6}$ Table I shows the prevalence of smoking among those included in the present analysis. The smokers were less likely to be employed in non-manual occupations and were more likely to drink more alcohol, but their blood pressure and body mass index were similar to those of non-smokers. (Alcohol, body mass index, and blood pressure might be expected to interact with dietary and biochemical variables in affecting the risk of chronic disease in smokers.

Table II shows the amounts of different foods consumed by the subjects. The foods were all those listed in the database made available to us. There was a stepwise increase from non-smokers to light smokers $(<20$ cigarettes a day) to heavy smokers ( $\geqslant 20$ cigarettes a day) among both men and women in the consumption of white bread, sugar, butter, and whole milk and decrease in the consumption of wholemeal bread and high fibre breakfast cereal. Non-smokers of both sexes ate more polyunsaturated margarine, carrots, and apples and pears than either group of smokers. Male non-smokers ate fewer sausages than either smoking group, while female non-smokers ate less meat products (particularly burgers and meat pies), fried white fish, and peas.

Table III shows the nutrient intakes of the different groups. Generally, smokers' diets were similar, and any significant differences were between non-smokers and both groups of smokers. Non-smokers of both sexes had higher intakes of polyunsaturated fats, protein, carbohydrate, fibre, iron, carotene, and ascorbic acid, although for women the difference in intake of polyunsaturated fat was significant only between non-smokers and heavy smokers. There were no significant differences between the groups in the total energy intake except that non-smoking women had a higher energy intake than light smokers. However, non-smokers of both sexes derived a significantly smaller proportion of their total energy intake from alcohol than did smokers and a significantly greater proportion from carbohydrate, while male nonsmokers also derived a greater proportion of their energy intake from protein. In addition, non-smokers derived a smaller proportion of their food energy

TABLE II-Consumption of different foods during one week by smoking status. Values are means (95\% confidence intervals) unless stated otherwise

\begin{tabular}{|c|c|c|c|c|c|c|c|c|}
\hline \multirow[b]{3}{*}{ Food type (g) } & \multicolumn{4}{|c|}{ Men } & \multicolumn{4}{|c|}{ Women } \\
\hline & \multicolumn{3}{|c|}{ Smoking status } & \multirow[b]{2}{*}{$\underset{\text { Value }^{\text {* }}}{\mathrm{p}}$} & \multicolumn{3}{|c|}{ Smoking status } & \multirow[b]{2}{*}{$\stackrel{p}{\text { Value }}$} \\
\hline & $\begin{array}{c}\text { None } \\
(n=631)\end{array}$ & $\begin{array}{c}\text { Light } \\
(<20 \text { cigarettes/day }) \\
(n=166)\end{array}$ & $\begin{array}{c}\text { Heavy } \\
(\geqslant 20 \text { cigarettes/day }) \\
(n=153)\end{array}$ & & $\begin{array}{c}\text { None } \\
(n=593)\end{array}$ & $\begin{array}{c}\text { Light } \\
(<20 \text { cigarettes/day }) \\
(n=193)\end{array}$ & $\begin{array}{c}\text { Heavy } \\
(\geqslant 20 \text { cigarettes/day }) \\
(n=106)\end{array}$ & \\
\hline White bread & $78.9(73.4$ to 84.4$) \dagger \ddagger$ & $97.2(85.8$ to $108 \cdot 6)$ & $97.3(85.6$ to 109.0$)$ & 0.001 & $42.8(39.5$ to 46.2$) \dagger \ddagger$ & $57 \cdot 3(51 \cdot 2$ to $63 \cdot 4)$ & $57 \cdot 7(49 \cdot 6$ to $65 \cdot 7)$ & $<0.001$ \\
\hline $\begin{array}{l}\text { Wholemeal bread } \\
\text { High fibre breakfast }\end{array}$ & $42 \cdot 6(37 \cdot 6$ to $47 \cdot 6) t \ddagger$ & $24 \cdot 3(16 \cdot 2$ to $32 \cdot 3)$ & $20.0(13.0$ to $27 \cdot 1)$ & $<0.001$ & $28.5(25.4$ to 31.5$) \dagger \ddagger$ & $17 \cdot 1(13.2$ to 20.9$)$ & $16.9(11.8$ to 22.0$)$ & $<0.001$ \\
\hline cereal & $20.4(17 \cdot 1$ to 23.6$) \dagger \ddagger$ & $8.8(5.5$ to 12.2$)$ & $8.1(4.5$ to 11.7$)$ & $<0.001$ & $15 \cdot 0(13.0$ to $17 \cdot 1) \dagger \ddagger$ & $9.9(6.3$ to 13.5$)$ & $5.9(3.0$ to 8.8$)$ & 0.001 \\
\hline Whole milk & $178.8(166$ to 192$)$ & $178.9(153$ to 205$)$ & $198 \cdot 3$ (173 to 224$)$ & 0.402 & $142.1(130.1$ to 154.1$) \dagger$ & $147 \cdot 3(126 \cdot 2$ to $168 \cdot 4)$ & $177 \cdot 4(150 \cdot 5$ to 204.3$)$ & 0.077 \\
\hline Eggs & $25 \cdot 9(24 \cdot 1$ to $27 \cdot 7)$ & $27.9(24.0$ to 31.8$)$ & $28.3(23.7$ to 32.7$)$ & 0.437 & $19.5(18.0$ to 21.0$)$ & $18.5(15.8$ to 21.3$)$ & $19.3(15.4$ to 23.2$)$ & 0.828 \\
\hline Butter & $7.0(6.2$ to 7.8$)$ & $7.3(5.6$ to 9.0$)$ & $8 \cdot 3(6.6$ to $10 \cdot 1)$ & 0.379 & $5.8(5.1$ to 6.5$) t$ & $7.0(5.6$ to 8.3$)$ & $8 \cdot 1(5.8$ to 10.4$)$ & 0.034 \\
\hline Polyunsaturated & & & & & & & & \\
\hline margarine & $5.9(5.0$ to 6.8$) \dagger \ddagger$ & $2.4(1.4$ to 3.4$)$ & $2.9(1.7$ to 4.1$)$ & $<0.001$ & $3.5(2.9$ to 4.1$) \dagger$ & $2.7(1.8$ to 3.5$)$ & $1.1(0.5$ to 1.7$)$ & 0.001 \\
\hline Meat products: & $134 \cdot 0(128$ to 140$)$ & $141 \cdot 6(131$ to 153$)$ & $139 \cdot 2(128$ to 151$)$ & 0.423 & $80.3(76.2$ to 84.3$) t \ddagger$ & $91.9(84.6$ to 99.1$)$ & $97.8(87.6$ to $108 \cdot 1)$ & 0.001 \\
\hline Burgers & $7.6(6.3$ to 8.8$)$ & $9 \cdot 4(6 \cdot 1$ to $12 \cdot 7)$ & $10.7(6.3$ to $15 \cdot 1)$ & $0 \cdot 154$ & $4.9(4.0$ to 5.8$) t$ & $5.2(3.6$ to 6.9$)$ & $8.4(4.2$ to $12 \cdot 6)$ & 0.031 \\
\hline Sausages & $12.2(10.8$ to 13.6$) t \ddagger$ & $17.5(14.3$ to 20.6$)$ & $16.6(13.6$ to 19.6$)$ & 0.001 & $7 \cdot 3(6.4$ to $8 \cdot 2)$ & $9 \cdot 1(7 \cdot 6$ to $10 \cdot 6)$ & $8.8(6.5$ to 11.1$)$ & 0.094 \\
\hline Meat pies & $25.3(22.8$ to 27.8$)$ & $25.8(21.0$ to 30.5$)$ & $29.6(23.8$ to 35.3$)$ & 0.341 & $10.7(9.3$ to $12 \cdot 2)$ tł & $17.9(14.4$ to 21.3$)$ & $17.7(13.5$ to 21.9$)$ & $<0.001$ \\
\hline Fried white fish & $14 \cdot 7(13 \cdot 1$ to $16 \cdot 3)$ & $12.8(10.0$ to 15.5$)$ & $13.1(10.4$ to $15 \cdot 8)$ & 0.404 & $8.4(7.4$ to 9.5$) t$ & $10.3(8.0$ to 12.6$)$ & $12.8(9.5$ to 16.0$)$ & 0.009 \\
\hline Potato chips & $49 \cdot 3(45.5$ to $53 \cdot 2)$ & $56.0(48.0$ to 64.0$)$ & $52.7(45.5$ to 59.9$)$ & 0.267 & $25.9(23.3$ to 28.5$) \dagger$ & $36.8(31.0$ to 42.6$) t$ & $50.9(42.6$ to 59.2$)$ & $<0.001$ \\
\hline Peas & $19 \cdot 1(17 \cdot 6$ to $20 \cdot 6)$ & $18 \cdot 8(15 \cdot 3$ to $22 \cdot 3)$ & $17 \cdot 8(14.4$ to $21 \cdot 1)$ & 0.754 & $13.5(12.3$ to 14.7$) t$ & $14.2(12.0$ to 16.4$)$ & $17.5(14.3$ to 20.6$)$ & 0.048 \\
\hline Carrots & $1.65(1.18$ to 2.13$)$ t‡ & $0.72(0.14$ to 1.30$)$ & $0.53(0.10$ to 0.96$)$ & 0.018 & $2.2(1.6$ to 2.8$)+\ddagger$ & $1.0(0.6$ to 1.4$)$ & $0.8(0.1$ to 1.4$)$ & 0.018 \\
\hline Apples and pears & $32.9(20 \cdot 1$ to $36 \cdot 6) t \neq$ & $16.6(12.0$ to 21.3$)$ & $16.0(10.7$ to 21.3$)$ & $<0.001$ & $34.0(30.6$ to 37.5$)$ tł & $20.9(16.6$ to 25.2$) t$ & $11.8(6.8$ to 16.8$)$ & $<0.001$ \\
\hline Sugar & $18.1(16.3$ to 20.0$)$ t‡ & $29.5(24.8$ to 34.2$) t$ & $41.9(35 \cdot 7$ to $48 \cdot 1)$ & $<0.001$ & $9.1(7.7$ to 10.4$)+\ddagger$ & $14.8(11.7$ to 17.9$) t$ & $24 \cdot 1(18.0$ to $30 \cdot 2)$ & 0.001 \\
\hline
\end{tabular}

${ }^{\star}$ Analysis of variance. $\nmid$ Significantly different from heavy smokers: $p<0.05$ least significance difference test. $\ddagger$ Significantly different from light smokers: $p<0 \cdot 05$ least significance difference test. 


\begin{tabular}{|c|c|c|c|c|c|}
\hline \multirow{3}{*}{ Nutrient intakes } & \multirow[b]{3}{*}{ None } & \multicolumn{2}{|l|}{ Smoking status } & \multicolumn{2}{|c|}{$\begin{array}{c}\text { Analysis of } \\
\text { variance }\end{array}$} \\
\hline & & Light & Heavy & & \\
\hline & & ( $<20$ cigarettes/day) & ( $\geqslant 20$ cigarettes/day) & $F$ ratio & $\mathrm{p}$ Value \\
\hline \multicolumn{6}{|c|}{ Men } \\
\hline No of subjects & 631 & 166 & 153 & & \\
\hline Energy (kJ) & $10422(10234$ to 10610$)$ & $10222(9805$ to 10640$)$ & $10170(970$ to 580$)$ & $0 \cdot 8$ & 0.414 \\
\hline Total fat $(\mathrm{g})$ : & $104.0(101.8$ to 106.2$)$ & $100.5(96.0$ to 105.0$)$ & $99 \cdot 8(95 \cdot 3$ to $104 \cdot 2)$ & $2 \cdot 0$ & $0 \cdot 140$ \\
\hline Saturated & $48 \cdot 1(46.9$ to $49 \cdot 2)$ & $47 \cdot 1(44 \cdot 7$ to $49 \cdot 6)$ & $47.7(45.4$ to $50 \cdot 0)$ & 0.3 & 0.761 \\
\hline Polyunsaturated & $16.6(16 \cdot 1$ to $17 \cdot 2) \dagger \ddagger$ & $14.4(13.5$ to 15.3$)$ & $13.7(12.8$ to 14.7$)$ & $14 \cdot 7$ & $<0.001$ \\
\hline Ratio* & $0.37(0.36$ to 0.39$) \dagger \neq$ & $0.32(0.30$ to 0.35$)$ & $0.30(0.28$ to 0.32$)$ & $9 \cdot 4$ & $<0.001$ \\
\hline Protein (g) & $87.4(85.9$ to 89.0$) t \ddagger$ & $81.1(77.9$ to 84.3$)$ & $79.2(76.082 .4)$ & $13 \cdot 8$ & $<0.001$ \\
\hline Carbohydrate (g) & $279 \cdot 6(273$ to 286$) \dagger \ddagger$ & $265.2(253$ to 277$)$ & $265 \cdot 8(252$ to 279$)$ & $3 \cdot 4$ & 0.035 \\
\hline Fibre (g) & $26.6(25.9$ to 27.4$) \dagger \ddagger$ & $22.5(21.3$ to 23.7$)$ & $21.6(20.5$ to 22.8$)$ & $28 \cdot 7$ & $<0.001$ \\
\hline Iron (mg) & $15.0(14.5$ to 15.4$) \dagger \ddagger$ & $12.5(11.9$ to 13.1$)$ & $12.3(11.6$ to 13.0$)$ & $22 \cdot 7$ & $<0.001$ \\
\hline Retinol $(\mu \mathrm{g})$ & $1309(1175$ to 1443$)$ & $1164(900$ to 1429$)$ & $1291(1007$ to 1575$)$ & 0.5 & 0.628 \\
\hline Carotene $(\mu \mathrm{g})$ & 2615 (2456 to 2773$) \dagger \ddagger$ & $1936(1705$ to 2168$)$ & 2233 (1899 to 2568 ) & $8 \cdot 8$ & 0.001 \\
\hline Ascorbic acid $(\mu \mathrm{g})$ & $81.7(75.4$ to 88.1$) \dagger \ddagger$ & $65.9(52.0$ to 79.7$)$ & $62.5(48.5$ to 76.5$)$ & $4 \cdot 6$ & 0.010 \\
\hline \multicolumn{6}{|c|}{$\%$ Of total energy from: } \\
\hline Total fat & $37.6(37.2$ to 38.0$)$ & $37 \cdot 1(36 \cdot 2$ to $38 \cdot 1)$ & $37 \cdot 1(36 \cdot 2$ to $38 \cdot 0)$ & 0.8 & 0.465 \\
\hline Protein & $14.4(14 \cdot 1$ to $14 \cdot 6) \dagger \ddagger$ & $13.6(31.2$ to 14.0$)$ & $13.3(12.9$ to 13.6$)$ & $10 \cdot 6$ & 0.001 \\
\hline Carbohydrate & $42 \cdot 1(41.6$ to 42.7$)$ & $41.0(40.0$ to 42.0$)$ & $41.0(39.8$ to 42.2$)$ & 3.0 & 0.048 \\
\hline Alcohol & $6.2(5.6$ to 6.7$)+\ddagger$ & $8.4(6.9$ to 10.0$)$ & $8.9(7.4$ to 10.3$)$ & $10 \cdot 0$ & $<0.001$ \\
\hline \multicolumn{6}{|c|}{$\%$ Of food energy from: } \\
\hline Total fat & $40 \cdot 1(39 \cdot 7$ to $40 \cdot 5)$ & $40.5(39 \cdot 8$ to $41 \cdot 2)$ & $40.7(39.9$ to 41.5$)$ & $1 \cdot 2$ & $0 \cdot 289$ \\
\hline \multirow[t]{2}{*}{ Saturated fat } & $18.5(18.2$ to 18.7$) \dagger$ & $18.9(18.4$ to 19.3$)$ & $19.4(18.9$ to 19.8$)$ & $5 \cdot 6$ & 0.003 \\
\hline & \multicolumn{3}{|c|}{ Women } & & \\
\hline No of subjects & 593 & 193 & 106 & & \\
\hline Energy (kJ) & 7245 (7105 to 7386$) \ddagger$ & 6909 (6654 to 7164$)$ & 6988 (6637 to 7340$)$ & $3 \cdot 1$ & 0.046 \\
\hline Total fat $(\mathrm{g})$ : & $75 \cdot 5(73.7$ to $77 \cdot 2)$ & $73.3(70 \cdot 1$ to 76.5$)$ & $73.5(69 \cdot 1$ to $77 \cdot 8)$ & 0.9 & 0.399 \\
\hline Saturated & $35.9(35.0$ to 36.0$)$ & $35.0(33.3$ to $36 \cdot 7)$ & $35.8(33.4$ to 38.3$)$ & 0.4 & 0.643 \\
\hline Polyunsaturated & $11.5(11.1$ to 11.9$) \dagger$ & $10.8(10.1$ to 11.5$) \dagger$ & $9.6(8.8$ to 10.3$)$ & 7.9 & 0.001 \\
\hline Ratio $^{\star}$ & $0.39(0.37$ to 0.40$) \dagger$ & $0.37(0.34$ to 0.39$) t$ & $0.32(0.29$ to 0.35$)$ & 6.9 & 0.001 \\
\hline Protein (g) & $64.4(63.3$ to 65.6$) \dagger \ddagger$ & $60 \cdot 1(57.9$ to 62.2$)$ & $60.2(57.3$ to 63.0$)$ & 8.8 & 0.001 \\
\hline Carbohydrate (g) & 200.0 (195 to 205$) t \ddagger$ & $184.0(176$ to 192$)$ & $190 \cdot 1$ (179 to 202$)$ & $6 \cdot 1$ & 0.002 \\
\hline Fibre (g) & $19.8(19.3$ to 20.4$) \dagger \ddagger$ & $17 \cdot 1(16 \cdot 3$ to $17 \cdot 8)$ & $16 \cdot 2(15 \cdot 2$ to $17 \cdot 2)$ & $26 \cdot 0$ & $<0.001$ \\
\hline Iron (mg) & $12.8(11.9$ to 13.8$) \dagger \ddagger$ & $10.7(9.5$ to 11.9$)$ & $10.1(8.6$ to 11.5$)$ & $5 \cdot 1$ & 0.006 \\
\hline Retinol $(\mu \mathrm{g})$ & 1208 (1074 to 1344$)$ & $1293(1022$ to 1565$)$ & $975(708$ to 1243$)$ & $1 \cdot 2$ & 0.293 \\
\hline Carotene $(\mu \mathrm{g})$ & 2359 (2192 to 2526$) \dagger \ddagger$ & 1766 (1585 to 1948$)$ & $1601(1321$ to 1881$)$ & $12 \cdot 5$ & $<0.001$ \\
\hline Ascorbic acid $(\mu \mathrm{g})$ & $82.8(73.6$ to 92.1$)$ & $57.5(51.9$ to 63.1$)$ & $45.9(38.0$ to 54.0$)$ & $9 \cdot 1$ & $<0.001$ \\
\hline \multicolumn{6}{|c|}{$\%$ Of total energy from: } \\
\hline Total fat & $39.1(38.7$ to 39.5$)$ & $39.8(39 \cdot 1$ to $40 \cdot 6)$ & $39 \cdot 4(38 \cdot 2$ to $40 \cdot 7)$ & $1 \cdot 6$ & $0 \cdot 212$ \\
\hline Protein & $15.3(15.0$ to 15.2$)$ & $14.9(14.5$ to 15.4$)$ & $14.9(14 \cdot 2$ to $15 \cdot 7)$ & $1 \cdot 3$ & 0.303 \\
\hline Carbohydrate & $43.2(42.8$ to 43.7$) \ddagger$ & $41.7(40.9$ to $42 \cdot 6)$ & $42 \cdot 6(41 \cdot 3$ to $44 \cdot 0)$ & 4.5 & 0.011 \\
\hline Alcohol & $2.4(2.1$ to 2.7$) \ddagger$ & $3.6(2.9$ to 4.3$)$ & $3 \cdot 2(2 \cdot 3$ to $4 \cdot 1)$ & 6.9 & 0.001 \\
\hline \multicolumn{6}{|c|}{$\%$ Of food energy from: } \\
\hline Total fat & $40.1(39.7$ to 40.5$)$ & $41.3(40.6$ to 42.0$)$ & $40.8(39.5$ to 42.0$)$ & $4 \cdot 2$ & 0.015 \\
\hline Saturated fat & $19.0(18.7$ to 19.2$) \ddagger$ & $19 \cdot 7(19 \cdot 2$ to $20 \cdot 1)$ & $19.7(18.9$ to 20.5$)$ & $4 \cdot 0$ & 0.018 \\
\hline
\end{tabular}

*Polyunsaturated fat: saturated fat.

†Significantly different from heavy smokers: $p<0.05$ least significance difference test.

$\ddagger$ Significantly different from light smokers: $p<0.05$ least significance difference test.

(energy from alcohol excluded) from saturated fats than did smokers.

The eating patterns described in table II were consistent with the differences in nutrient intake: intake of fibre was associated with lower consumption of wholemeal bread; lower intake of polyunsaturated fat was associated with lower consumption of polyunsaturated margarine, and lower intake of carotene was associated with lower consumption of carrots.

Biochemical measures have been reported in detail elsewhere. ${ }^{6}$ There was a significant correlation between dietary intake of carotene and serum $\beta$ carotene concentration in all subjects in the study $(r=0.26$, $\mathrm{p}<0.01$ ), although the relation was strongest in nonsmokers $(r=0.33, \mathrm{p}<0.001)$ and weakest in light smokers $(r=0.09, \mathrm{p}>0.05)$.

To determine whether differences in other covariates influenced the differences in nutrient intakes and biochemical measures between non-smokers and smokers we made an analysis of covariance-adjusting for age, gender, region, occupation group, alcohol consumption, height, and weight - and calculated the adjusted mean estimates. Adjustment for the above factors made a small difference to the mean levels for some measurements, but it did not alter the overall pattern of differences between non-smokers and smokers. However, adjustment for energy intake in addition to the other covariates-by addition of energy intake to a regression analysis- changed the results for fat intake: before adjustment smokers had lower intakes of total and saturated fat, but after adjustment they had significantly higher intakes (non-smokers $88.9 \mathrm{~g}$ total fat, light smokers $90.7 \mathrm{~g}$, heavy smokers $90 \cdot 4 \mathrm{~g}$; Fratio $4 \cdot 9, \mathrm{p}=0 \cdot 01$ ).

\section{Discussion}

The dietary and nutritional survey of British adults is one of the largest studies in which the most precise method available for assessing dietary intake has been used in a representative sample of the British population. ${ }^{6}$ The exceptional quality of the data from the study allowed us to examine interactions between dietary, biochemical, and anthropometric measures to see how diet and smoking interact to influence the risk of chronic disease. A potential weakness of the study was that non-smokers were not separated into those who had never smoked and those who were ex-smokers. Other studies have shown that the diets of these two groups might be different, although the differences are probably less than those between either group and current smokers. ${ }^{89}$ The inclusion of ex-smokers with those who had never smoked would tend to reduce the differences seen between smokers and non-smokers.

\section{DIFFERENT EATING PATTERNS}

The dietary and nutritional differences reported here are similar to those reported from other studies. ${ }^{28-11}$ The differences were generally quite large and internally consistent with the data on food intake matching the nutrient data and showing general agreement with the biochemical measures. Adjustment for age, sex, occupation group, region, alcohol consumption, weight, and height did not alter the differences in dietary intakes and biochemical measures seen between smokers and non-smokers. The consistency of the data with previously published studies suggests that it might be reasonable to extrapolate inferences drawn from this study to the population at large. There 
was little difference in the total food energy among the groups, but the quality of the macronutrients is important: the extent to which carbohydrate is taken as fibre or simple sugars, the ratio of polyunsaturated to saturated dietary fats, and the relative contribution of protein to total energy. These differences in nutrient intake reflect different eating patterns, with foods contributing to fibre intake being important in differentiating between smokers and non-smokers. The intake of macronutrients and the food sources of the macronutrients differentiated smokers from non-smokers, and in absolute terms the differences were greater for protein and fibre intake than for fat intake.

\section{DIFFERENT METABOLIC DEMANDS}

Caution should be exercised in drawing causal inferences from cross sectional data, but the present analysis suggests that smokers have different patterns of food intake, which leads to differences in nutrient intake, and that their metabolic handling of dietary nutrients is different. Smoking generates about $10^{15}$ free radicals with each puff, which inevitably places an increased demand on the antioxidant systems that protect cells from damage by free radicals. ${ }^{12}$ Smokers have lower intakes of foods which provide antioxidant micronutrients and lower intakes of antioxidants such as carotene and ascorbic acid. For the same level of dietary intake of carotene, smokers have lower circulating levels of $\beta$ carotene than non-smokers, consistent with the proposal that the carotene is consumed excessively in smokers because of an increased demand for antioxidants. The data suggest that the dietary intake of smokers and the metabolic effects of smoking on nutrient metabolism increase the risk of oxidative tissue damage in smokers above that which might be expected from the free radicals generated by smoking itself.

\section{GREATER TISSUE DAMAGE}

Smokers have higher serum concentrations of low density lipoprotein cholesterol. ${ }^{6}$ It has recently been suggested that oxidised low density lipoprotein is more likely to be taken up by monocytes and macrophages to form foam cells and lead to atheroma. ${ }^{4}$ Smokers have a greater potential for low density lipoprotein to be oxidised, as indicated directly by the reduced tocopherol:cholesterol ratio compared with nonsmokers. Therefore, smokers would be expected to be at increased risk of atheroma and heart disease not only because they have higher serum concentrations of low density lipoprotein but also because at the same concentration of low density lipoprotein smokers are likely to have more oxidised low density lipoprotein.

There are higher circulating concentrations of other acute phase reactants such as caeruloplasmin in smokers compared with non-smokers, supporting the suggestion that in smokers there is ongoing tissue damage and cytokine production. ${ }^{13}$ Tissue damage caused by free radicals would generate an inflammatory response which enhances the generation of free radicals and leads to further tissue damage. Vascular changes induced by cytokines might contribute to the atherogenic process. ${ }^{14}$ Recent studies have shown that in rabbits the stimulation of mRNA for cytokines in the aorta requires a combination of an appropriate pattern of dietary fatty acids and the presence of a damaging stimulus. ${ }^{15}$ In rats it has been shown that the inflammatory response might be critically modulated by the pattern of fatty acids taken in the diet. ${ }^{16}$ Furthermore, many of the positive acute phase proteins exert antioxidant activity, and the ability to produce adequate amounts of critical antioxidants can be influenced by the overall state of

\section{Public health implications}

- Tobacco smoke contains high concentrations of free radicals, which places extra demands on a smoker's antioxidant systems that protect cells from damage by free radicals

- Such systems, however, depend on the dietary intake of antioxidants

- In a study of the diets of a representative sample of British people smokers tended to eat more processed foods, sugar, and butter than non-smokers and less fibre, polyunsaturated fats, protein, fruits, and vegetables

- In particular, smokers had lower intakes of antioxidants such as carotene and ascorbic acid

- The poor diets of smokers probably exacerbate the damage caused by their smoking

the defence systems, in particular the tocopherol status. ${ }^{17}$

\section{CONCLUSION}

The interaction between nutrients and smoking appears to influence three related processes: enhanced free radical induced damage as a consequence of an increased load and reduced defences; increased concentrations of circulating lipids at greater risk of peroxidative damage; and a low grade inflammatory response indicative of ongoing tissue damage. Smokers are at higher risk of chronic disease not only because of their dietary patterns but also because of the extra demands placed on the nutrient supply by the effects of smoking itself. The mechanistic basis of these complex interactions needs to be explored at the tissue and cellular level.

This analysis was carried out with the support of the Department of Health. We thank the Ministry of Agriculture, Fisheries and Food for access to the database; and Dr Mike Campbell and Mr Mark Mullee, Medical Statistics and Computing, University of Southampton, for advice and help in reading data files.

1 Department of Health. On the state of the public health: the annual report of the chief medical officer of the Department of Health for the year 1991. London: HMSO, 1992.

2 Thompson RL, Margetts BM, Wood DA, Jackson AA. Cigarette smoking and food and nutrient intakes in relation to coronary heart disease. Nutrition Research Reviews 1992;5:131-52.

3 Halliwell B. Cigarette smoking and health: a radical view. $f R$ Soc Health 1993;113:91-6.

4 Steinberg D, Parthasarthy S, Carew TE, Khoo JC, Witzrurm JL. Beyond cholesterol: modifications of low-density lipoproteins that increase its cholesterol: modifications of low-density lipop

5 Carroll KK, Parenteau HI. A proposed mechanism for effects of diet on mammary cancer. Nutr Cancer 1991;16:79-83.

6 Gregory J, Foster $\mathrm{K}$, Tyler $\mathrm{H}$, Wiseman M. The dietary and nutritional survey of British adults. London: HMSO, 1990.

7 Kish L. Survey sampling. London: Wiley, 1965.

8 Cade J, Margetts BM. The relationship between diet and smoking: is the diet of smokers different? $\mathcal{F}$ Epidemiol Community Health 1991;45:270-2.

9 Wichelow MJ, Erzinclioglu SW, Cox BD. A comparison of the diets of nonsmokers and smokers. Br F Addict 1991;86:71-81.

10 Bolton-Smith C, Woodward M, Brown CA, Tunstall-Pedoe H. Nutrient intake by duration of ex-smoking in the Scottish Heart Study. $\mathrm{Br} \mathcal{F}$ Nutr 1993;69:315-32.

11 Strickland D, Graves K, Lando H. Smoking status and dietary fats. Prev Med 1992;21:228-36

12 Church DF, Pryor WA. Free-radical chemistry of cigarette smoke and its toxicological implications. Environ Health Perspect 1985;64:111-26.

13 Bridges RB, Chow CK, Rehm SR. Micronutrient status and immune function in smokers. Ann N Y Acad Sci 1990;587:218-39.

4 Hajiar DP, Pomerantz B. Signal transduction in atherosclerosis: integration of cytokines and the eicosanoid network. FASEB $\mathcal{1}$ 1992;6:2933-41.

15 Fleet JC, Clinton SK, Salomom RN, Loppnow H, Libby P. Atherogenic diets enhance endotoxin-stimulated interleukin-1 and tumour necrosis factor gene expression in rabbit aortae. $\mathcal{F}$ Nutr 1992;122:294-305.

16 Mulroney HM, Grimble RF. Influence of butter and of corn, coconut and fishoils on the effects of recombinant human tumour necrosis factor- $\alpha$ in rats. Clin Sci 1993;84:105-12.

17 Troughton KL, Grimble RF. Vitamin E status modulates the inflammatory response to endotoxin in rats [abstract]. Proc Nutr Soc 1993;52:84A.

(Accepted 10 September 1993) 